\title{
Sinderes
}

\section{La ética en la educación colombiana: reflexiones desde la categoría "maestro como intelectual transformativo"}

\author{
Ethics in Colombian education: Reflections from \\ "Teacher as a transformative intellectual" category
}

\begin{abstract}
Autores
Cristian Andrés Zapata Vélez ${ }^{2}$

Recibido: 4 de noviembre de 2017.

Aprobado: 28 de noviembre de 2017.
\end{abstract}

\section{Resumen}

Este trabajo se enmarca en ese hiato entre un ethos mestizo, moderno e individualista y una legislación liberal, tecnocrática y progresista. Su foco es la educación en ética y el documento que la reglamenta: los lineamientos curriculares para la enseñanza de la ética del Ministerio de Educación Nacional (MEN). Su referente teórico son las teorías del currículum, y su objetivo es reflexionar sobre la cuestión de la enseñanza de la moral con el foco ya mencionado, a través de la defensa de la figura del maestro como intelectual transformativo tomada de Henry Giroux. La idea, entonces, es mostrar que esta figura es la más adecuada para llevar a cabo el ideal de educación moral de Esperanza Guisán y, por tanto, sortear el quiebre entre dos conjuntos de valores discordantes, gracias a la apropiación de algunas ideas que aparecen en los lineamientos curriculares para la enseñanza de la ética, de tal suerte que se logre hacer una práctica transformadora sin tener que alejarse del marco legal colombiano. 
Palabras clave: ética, educación, maestro, intelectual transformativo.

\section{Abstract}

This work is defined in a break between a mestizo, modern and individualist ethos and a liberal, technocratic and progressive legislation. It focusses on the education in ethics and the paper that rules it: the curricular guidelines for the teaching of ethics of the Colombian National Education Ministry. Its theoretical reference is the curriculum theories, and its objective is to reflect on the question of the teaching of morality, with the above focus, through the defense of the figure of the teacher as a transformative intellectual, taken from Henry Giroux. The idea is to show that the teacher as a transformative intellectual is the most appropriate figure to carry out the ideal of moral education from Esperanza Guisán. Therefore, teacher can overcome the break between two sets of discordant values, thanks to the appropriation of some ideas that appear in the curricular guidelines for the teaching of ethics. Thus, a transforming practice can be achieved without having to move away from the Colombian legal framework.

Key words: Ethics, education, teacher, transformative intellectual.

\section{Introducción}

La pregunta por la formación moral de los colombianos no es en absoluto novedosa, de hecho su origen se remonta a finales del siglo XIX, cuando el Estado comenzó a preocuparse por la educación del pueblo. Pero habría que dar una mirada histórica a nuestro ethos para poner de manifiesto las circunstancias que llevaron al Estado a esta preocupación. Es necesario decir, para comenzar, que estas latitudes, antes habitadas por numerosas tribus indígenas, fueron colonizadas por el Imperio español. Lo particular de esta colonización es que los españoles que llegaron a América comenzaron a mezclarse con los nativos, no solo copulativamente sino también culturalmente. Esto llevó a que en los terrenos de lo que hoy se conoce como Colombia se constituyera un ethos mestizo que combinaba las ideas propias de la Europa de ese tiempo, la fuerte carga religiosa de los españoles y las tradiciones autóctonas de los nativos.

Este mestizaje se siguió dando hasta la época de la Independencia cuando "el conflicto de la elite criolla neogranadina con la administración colonial, hizo que ésta se identificara muy tempranamente con las ideas del liberalismo europeo y de la ilustración" (Ministerio de Educación Nacional, 2011, p. 21). Este hecho tuvo repercusiones económicas, políticas y sociales. Económicas, en la aceptación del modelo liberal anglosajón; políticas, en el impulso de las ideas independistas, y sociales, en la relativa autonomía de las élites económicas frente al Estado, lo que impedía a este último ser un mediador efectivo en las problemáticas sociales. 
Todas estas cuestiones prefiguraban el ethos mestizo de la naciente nación colombiana, a las que habría que sumarle un factor que tuvo la mayor influencia en las cuestiones morales durante los siglos XIX y XX, esto es, las relaciones entre Iglesia y Estado. Estas relaciones, heredadas de la Colonia, supusieron "un tutelaje de la Iglesia sobre los más diversos órdenes no sólo en lo político, sino también en lo social y en consecuencia naturalmente en lo moral, en el ámbito de los ideales, las normas sociales y las costumbres” (MEN, 2011, p. 22). Pero esta alianza tuvo su más poderosa influencia gracias a la Constitución de 1886 en la cual se concedió lo que se conoce como el Concordato, “en el que entre otros acuerdos se entregó la función estatal de la educación a la Iglesia Católica y consolidó el presupuesto de que el Estado y la moral tenían necesariamente una fundamentación religiosa” (MEN, 2011, p. 22).

Ahora bien, frente a todos estos factores, que han creado un ethos mestizo anclado a ideas modernas, surge la Constitución política de 1991, la cual puso a los colombianos frente a un nuevo paradigma que tocó todos los aspectos de la nación (sociales, políticos, económicos, culturales), pero principalmente (para los intereses de este trabajo) el educativo. "La carta [magna] sugiere la creación de un nuevo país fundado en los principios de la democracia participativa, en el respeto y valoración a las diferencias de todo orden y en los valores de la justicia, la libertad, la igualdad y la solidaridad" (MEN, 2011, p. 60). Producto de estos principios nació la Ley 115 de 1994 en la que se plasman los fines y objetivos de la educación nacional, y por consiguiente de la educación en ética y valores humanos.

Este trabajo se enmarca en ese hiato entre un ethos mestizo, moderno e individualista y una legislación liberal, tecnocrática y progresista. Su foco es la educación en ética y el documento que la reglamenta: los lineamientos curriculares para la enseñanza de la ética del Ministerio de Educación Nacional (MEN). Su referente teórico, las teorías del currículum, y su objetivo es entonces reflexionar sobre la cuestión de la enseñanza de la moral con el foco ya mencionado, a través de la defensa de la idea de que la figura del maestro como intelectual transformativo, tomada de Henry Giroux (1997), es la más adecuada para llevar a cabo el ideal de educación moral de Esperanza Guisán (1995), y por tanto, sortear el hiato entre dos conjuntos de valores discordantes gracias a la apropiación de algunas ideas que aparecen en los lineamientos curriculares para la enseñanza de la ética, de tal suerte que se logre hacer una práctica transformadora sin tener que alejarse del marco legal colombiano.

Este objetivo marca un trazado de ruta que requiere un análisis triádico de los elementos antes mencionados (ética, currículo y políticas educativas), en el que los tres se condicionan e interrelacionan. Así, primero se presenta un ideal de educación ético defendido por toda una tradición filosófica que se fundamenta en la naturaleza misma de la reflexión filosófica por la moral, luego se muestra que la idea del maestro como un intelectual transformativo se complementa muy bien con el ideal postulado y, finalmente, se analiza si en las políticas educativas hay un marco de posibilidad para que este ideal pueda ser puesto en práctica. 


\section{El problema de la educación moral en la filosofía}

Según la agenda pactada en el párrafo anterior, la primera tarea de este artículo es ilustrar respecto a la pregunta por la educación moral, para saber qué limitaciones pone el objeto de estudio - la moral - a la praxis educativa y qué exigencias demanda de ella. Parece ser que la primera formulación de la pregunta filosófica por la educación moral fue la que le remitió Menón a Sócrates en el diálogo platónico que lleva el nombre de aquél (Platón, 1988). Cuando se comenzó a indagar en este diálogo sobre si era enseñable la virtud se dio origen a una larga tradición que se dedicó a investigar la cuestión, pero el asunto se mostró tan complejo que aún hoy persiste el interrogante por cómo educar moralmente a las nuevas generaciones.

Esta pregunta tiene unas bases antropológicas profundas, pues supone una perfectibilidad del ser humano. Quien mejor ha defendido tal tesis ha sido el filósofo alemán Immanuel Kant, el cual parte de un dato antropológico fundamental: la finitud de la vida del hombre, lo que hace de la educación una necesidad humana. Los hombres somos seres finitos y, por tanto, para perpetuar la especie tenemos que educar a nuestros vástagos de modo que la vida en sociedad no se tenga que recrear cada generación. Esta circunstancia es tratada por Kant (1991) en la Pedagogía, donde el filósofo de Königsberg recurre a la comparación con los animales para evidenciar las particularidades del hombre. Para él, los animales, contrario a lo que sucede con el hombre, son seres incapaces de perfectibilidad debido a que un animal ya lo es todo. A este respecto nos dice Bustamante:

Parece extraña esta idea de que "un animal ya lo es todo", pues crece, se desarrolla, muta, se reproduce, muere [...] Sí, pero la mirada del filósofo (y la imagen del poeta) está puesta más allá: todos esos cambios no transforman lo que el animal ya es desde el comienzo y no dejará de ser: anhelará la carne, aparte de los acontecimientos, si los de su especie la anhelan; buscará a los semejantes, más allá de las vicisitudes de su desarrollo, si los de su especie son gregarios; copulará, independientemente de las circunstancias, si los de su especie despliegan ciertos indicios. Nada hay por llenar en su ser: ya lo es todo (2012, p. 159).

Por el contrario, el ser humano necesita perfeccionarse, desarrollar sus potencialidades, desplegar todo su ser, llegar a ser lo que aún no es pero que tiene la potencia para serlo. La herramienta por antonomasia para ayudar al hombre en su realización es sin duda la educación. Además, en el hombre hay otro rasgo que es ajeno a los animales, la moralidad. Y si conjugamos esta particularidad con la cuestión de la finitud volvemos al problema de la educación moral.

La respuesta que dio Kant (1991) a la cuestión de la educación moral fue la de otorgar una fuerte carga a la razón, y más precisamente al autogobierno por medio de ella, a lo que llamó autonomía. Esta idea se ve condensada en un breve texto que salió a finales del siglo XVIII bajo el título Respuesta a la pregunta ¿qué es la ilustración? Allí Kant (1994) afirma que: 
La ilustración es la salida del hombre de su autoculpable minoría de edad. La minoría de edad significa la incapacidad de servirse de su propio entendimiento, sin la guía de otro. Uno mismo es culpable de esta minoría de edad cuando la causa de ella no reside en la carencia de entendimiento, sino en la falta de decisión y valor para servirse por sí mismo de él sin la guía de otro. iSapere aude! iTen valor de servirte de tu propio entendimiento! He aquí el lema de la ilustración (p. 7).

Este ímpetu kantiano gobernó toda la modernidad ${ }^{3}$ hasta que el auge del positivismo lógico en el siglo XX introdujo cuestiones gnoseológicas a la pregunta por la educación moral. Esto hizo que surgieran corrientes como el intuicionismo moral. En la actualidad se suele denominar intuicionista a quien sostiene:

[...] una concepción particular sobre la forma en que llegamos a determinar qué acciones son correctas y cuáles incorrectas. Los intuicionistas en este sentido afirman que aprehendemos los principios morales básicos por intuición, algo en lo que se puede creer sin pensar que exista más de un principio semejante (Dancy, 1995, p. 555).

O sea que para los intuicionistas los principios morales son innatos y autoevidentes, es decir que no necesitan demostración.

Sostener el intuicionismo permitiría dejar de lado la cuestión de la educación moral, pues cada cual nacería con los principios morales necesarios para la convivencia, por lo que la intervención de terceros sería innecesaria. Así, frente al intuicionismo surgen dos cuestiones: ¿son los principios morales cosas verdaderas o falsas, y en ese sentido cognoscibles? Y en caso de ser afirmativo lo anterior, ¿cómo son conocidos estos principios? ¿Existe alguna facultad especial para conocerlos?

Los llamados no cognitivistas afirman que las actitudes morales son expresiones de la posición moral del individuo y como tales pueden ser sinceras o no serlo, pueden ser congruentes o incongruentes con otras semejantes, pero nunca verdaderas o falsas, pues sólo el conocimiento es susceptible de ser calificado como verdadero o falso. En ese orden de ideas, para estos pensadores los principios morales no pueden ser ni verdaderos ni cognoscibles.

Sin embargo, hay un segundo grupo de pensadores intuicionistas que mantienen la posición contraria (Ross y Prichard son un buen ejemplo); según ellos, hay una ontología de los hecho morales, es decir, lo moralmente correcto existe en el mundo como hechos y la forma en la que nosotros los aprehendemos es lo suficientemente firme como para ser catalogado como conocimiento. Pero esta posición también es discutible, pues

\footnotetext{
3 Evidentemente paralelas a la postura kantiana se mantuvieron otras posiciones sobre la moral, entre las que es digna de ser destacada el utilitarismo, defendido principalmente por autores anglosajones y que tenía su énfasis puesto en el principio de la utilidad como criterio último de las acciones morales.
} 
Si existen estos hechos morales, ¿cómo llegamos a conocerlos? La afirmación de que se conocen por intuición parece sugerir que tenemos una facultad moral que nos revela la verdad moral de forma parecida a como nuestros ojos revelan verdades acerca de nuestro entorno. Si pensásemos esto, tenderíamos a acusar de ceguera moral a quienes disienten moralmente de nosotros; su facultad moral no gozaría de buena salud, como se comprueba en el hecho de que sus ideas difieren de las nuestras (Dancy, 1995, p. 556).

Todas estas dificultades hacen del intuicionismo una teoría moral difícil de sostener. Si el intuicionismo no es lo suficientemente sólido para justificar nuestros juicios morales, tenemos que volver a la pregunta por la educación moral, ya que esta es una cuestión inalienable para la ética. Así lo ve Esperanza Guisán, quien en su Introducción a la ética (1995) hace un especial énfasis en que "una de las tareas más importantes de la ética, tal vez la más importante de todas, es colaborar en el proceso del desarrollo moral, con objeto de que devengamos individuos autónomos, libres y críticos, con capacidad de auto-legislarnos" (p. 87), lo que trae a colación nuevamente los ideales kantianos.

Hay dos formas por excelencia para cumplir esta tarea de la ética: la primera de ellas es la socialización, la segunda es la educación moral o moralización. Con respecto a la primera, ha de decirse que no es un deber propiamente de la ética sino, más bien, una realización natural del hombre; pues él, nos dice Kant (1991), nace animal y es el deber de la educación dotarlo de humanidad. La socialización corresponde a ese primer momento educativo que lleva al hombre desde su nacimiento a su relación con los otros con los que se ve obligado a convivir, para inscribirlo en una sociedad, gracias a la apropiación del lenguaje. La socialización no es tarea exclusiva de la ética, sino que incluye también a la familia, la sociedad y la cultura.

Con respecto a la moralización, aunque es un trabajo mancomunado, es de plena competencia de la ética. En el proceso de moralización el hombre ha de darse cuenta de que sus relaciones con los demás trascienden el ámbito de la legalidad, y que existen unos códigos de conducta morales que ha de aprehender e interiorizar para ser considerado parte íntegra de la comunidad moral. Pero la moralización, en el sentido que la emplea Guisán (1995), no se limita únicamente a lo anteriormente descrito, sino que involucra también la exigencia que se hacen los miembros de la comunidad moral de las razones del obrar, y está en ellos decidir si las razones son válidas o no.

Aquí entran en juego los sentimientos morales. Si los sistemas morales son, como sugiere Guisán, sistemas de exigencias recíprocas, entonces "lo que pasa a una persona cuando no actúa como debe es la reacción afectiva (real o posible) de los demás" (Tugendhat 2007, p. 102). Estos afectos son compartidos, ya que sólo podemos tenerlos si suponemos que los otros miembros de la sociedad moral deberían tenerlos igualmente. Lo que sucede entonces es que 
[...] cuando alguien infringe una norma aceptada por esta sociedad, los otros reaccionan con un afecto negativo, el cual podemos llamar indignación. [...] El sentido de culpa es el correlato del sentimiento de indignación, pues en dicho sentido se anticipa la indignación de los demás (Tugendhat, 2007, p. 102).

De ahí que una educación ética deba considerar tanto el proceso de socialización como el de moralización, lo cual exige considerar tanto el lugar de la razón como el de los sentimientos en la ética, de tal forma que el sujeto a formar sea íntegro.

En este punto la ética (filosofía moral) y la educación se alían para resolver esta espinosa pregunta que, como ya se dijo, es tan antigua como compleja. Como el referente teórico de este trabajo son las teorías curriculares, lo que sigue es tratar la pregunta: ¿qué se puede decir desde este referente teórico frente a la pregunta por la educación moral? Para responderla se apela a las ideas del pedagogo francés Henry Giroux.

\section{El maestro como intelectual transformativo}

Giroux cree que "contrariamente a muchos movimientos de reforma educativa del pasado, el llamamiento actual al cambio educativo representa al mismo tiempo una amenaza yun desafío para los profesores de la escuela pública, en una medida realmente desconocida hasta ahora en la historia de nuestra nación" (1990, p. 171). La amenaza viene dada por las posibles consecuencias negativas para el quehacer docente que se pueden derivar de algunas de las reformas educativas que se han venido haciendo. Estas reformas, sustentadas en ideologías tecnocráticas e instrumentalistas, generan una división del trabajo altamente desventajosa para los maestros, pues se da una

[...] proletarización del trabajo del profesor, es decir, la tendencia a reducir a los profesores a la categoría de técnicos especializados dentro de la burocracia escolar, con la consiguiente función de gestionar y cumplimentar programas curriculares en lugar de desarrollar o asimilar críticamente los currículos para ajustarse a preocupaciones específicas (Giroux, 1997, p. 61).

A esta visión de la escuela y el quehacer docente las denomina el autor "pedagogías de la gestión" (Giroux, 1997, p. 63). En lo que sigue se presenta una visión general de este tipo de pedagogías y sus respectivas críticas a través de la categoría de intelectual, para luego enseñar cómo esas características se muestran deseables para un docente de ética según el ideal planteado en el parágrafo anterior.

En las llamadas "pedagogías de la gestión” se parte de una visión según la cual el maestro es sólo un técnico del currículo, un mero aplicador cuya tarea es hacer que los contenidos que se le imponen lleguen efectivamente a los sujetos que están a su cargo, los estudiantes. A esta concepción, altamente conductista, instrumentalista y tecnocrática, subyace un supuesto erróneo, a saber, “que todos los estudiantes pueden aprender utilizando los mismos materiales, las mismas técnicas de impartir instrucciones en el aula y las mismas modalidades de evaluación" (Giroux, 1997, pp. 63-64). Además, este supuesto va acompañado de tres postulados pedagógicos que lo respaldan: 
[...] la llamada a separar la concepción de la ejecución; la estandarización del conocimiento escolar con vistas a una mejor gestión y control del mismo; y la devaluación del trabajo crítico e intelectual por parte de profesores y estudiantes en razón de la primacía de las consideraciones prácticas (Giroux, 1997, p. 62).

De tales postulados se derivan, entonces, unos objetivos, medios, métodos y metas para la educación que reducen la escuela a un lugar de mera transmisión de conocimientos y, consecuentemente, a formar a los educadores de esas escuelas de manera acrítica, instrumentalista y conductista. Por otro lado, "la idea de que los estudiantes presentan diferentes historias y encarnan diferentes experiencias, prácticas lingüísticas, culturas y talentos no alcanza ninguna importancia estratégica dentro de la lógica y del alcance explicativo de la teoría pedagógica gestionaría" (Giroux, 1997, p. 64).

Asimismo, se les otorga todo el poder de las decisiones curriculares a los expertos, que crean el currículo por fuera de los contextos específicos de las escuelas, de tal modo que surjan "materiales curriculares a prueba del profesor" (Goodman, citado en Giroux, 1997, p. 63). Se podría resumir la postura de las "pedagogías de la gestión" en la pregunta: "¿Cómo asignar los recursos (profesores, estudiantes y materiales) para conseguir que se gradúe el mayor número posible de estudiantes dentro de un espacio de tiempo determinado?" (Apple, citado en Giroux, 1997, p. 63).

Si a este tipo de educación la enfrentamos con el ideal de la formación ética de Guisán (1995) (que devengamos individuos autónomos, libres y críticos, con capacidad de autolegislarnos) vemos que se muestra completamente ineficiente, pues de las "pedagogías de la gestión" se siguen sujetos acríticos, enajenados y heterónomos. Acríticos, porque los contenidos que se enseñan están permeados por una visión instrumentalista y tecnocrática del acontecer escolar; enajenados, porque la forma técnica en la que los maestros imparten sus clases les internaliza a los estudiantes una lógica de subordinación y obediencia; y heterónomos, porque la permanente coartación de su libertad los hace dependientes de la voluntad de otro.

Como vemos, las "pedagogías de la gestión" y la formación en ética son incompatibles. Pasamos a analizar la compatibilidad de la propuesta de Giroux $(1990,1997)$ con el ideal ético que tenemos como guía. Para Giroux la categoría de intelectual resulta útil por tres motivos principales: uno teórico, uno ideológico y otro profesional. En primer lugar, la categoría de intelectual presenta una base teórica que permite pensar una alternativa para el trabajo docente frente a la racionalidad tecnocrática que domina hoy el ámbito educativo. En segundo lugar, brinda los supuestos ideológicos y prácticos básicos para que los docentes puedan actuar efectivamente como intelectuales o, dicho de otro modo, permite articularse con el motivo anterior para que se dé un efectivo tránsito de la teoría a la práctica. Finalmente, reclama nuevamente para el docente un papel central en la construcción del currículo como agente que lo lleva a la práctica, lo cual implica reconocer y legitimar los diversos intereses políticos, económicos y sociales que están implicados en las decisiones y apuestas curriculares. 
Pero ¿cuáles son las características propias de un intelectual? Y, más precisamente, ¿qué tipo de personaje es un maestro como intelectual transformativo? Pues bien, en primera instancia, y en concordancia con todo lo anterior, la figura del intelectual permite descartar de entrada cualquier limitación del maestro como mero técnico del currículo, es decir que la figura del intelectual protege el trabajo docente de proletarizarse. Además, el carácter de intelectual le reconoce al maestro un saber propio que lo caracteriza, los intelectuales son "hombres y mujeres libres con una especial dedicación a los valores de la inteligencia y al crecimiento de la capacidad crítica de los jóvenes” (Scheffler, citado en Giroux, 1997, p. 64).

Igualmente, los maestros como intelectuales deben recurrir, en sus procesos de enseñanza, a métodos críticos y reflexivos, esto implica a su vez tornar su quehacer en crítico y reflexivo, lo que genera una continua revisión y mejora del propio trabajo, y lleva a los estudiantes a que adopten esas mismas actitudes. "Si los profesores han de educar a los estudiantes para ser ciudadanos activos y críticos, deberían convertirse ellos mismos en intelectuales transformativos" (Giroux, 1997, p. 65). Finalmente, en concordancia con la función transformadora del maestro, y siguiendo la idea de que las decisiones curriculares implican decisiones de poder, el maestro debe estar comprometido con principios democráticos y poseer una postura política clara.

Por otro lado, la figura del intelectual recupera para el maestro el privilegio, pero a la vez la responsabilidad, de pensar el currículo de manera crítica, reflexionar en torno a la forma en la que ese currículo debe ser enseñado y sobre los objetivos que debe perseguir. Esto implica revisar la visión tradicional de la escuela y pensar que las escuelas son:

[...] lugares que representan formas de conocimiento, usos lingüísticos, relaciones sociales y valores que implican selecciones y exclusiones particulares a partir de la cultura general. Como tales, las escuelas sirven para introducir y legitimar formas particulares de vida social. Más que instituciones objetivas alejadas de la dinámica de la política y el poder, las escuelas son de hecho esferas debatidas que encargan y expresan una cierta lucha sobre qué formas de autoridad, tipos de conocimiento, regulación moral e interpretaciones del pasado y del futuro deberían ser legitimadas y transmitidas a los estudiantes (Giroux, 1997, p. 65).

Esto abre todo un abanico de nuevas posibilidades para la escuela. Todas estas características se requieren para poder hablar del maestro como intelectual transformativo; sin embargo, el componente central de esta idea "es la necesidad de conseguir que lo pedagógico sea más político y lo político más pedagógico” (Giroux, 1997, p. 65). Esta doble exigencia permite articular la escuela y la sociedad y demanda cosas específicas de cada uno de estos ámbitos. Por un lado, a la escuela le exige volver sus espacios políticos, tomar conciencia de que la instrucción escolar lleva consigo decisiones políticas, decisiones de poder, que las luchas al interior de la escuela tienen repercusiones en la sociedad, y que su objetivo es preparar a los estudiantes para la vida en sociedad. Por otro lado, se le exige a la sociedad servirse más de la pedagogía, 
adoptar concepciones pedagógicas que reconozcan la naturaleza liberadora de la educación, que permita crear sujetos críticos y activos que lleven a cabo una verdadera transformación social. Esto exige de los intelectuales transformativos tomar en serio a los estudiantes, otorgarles voz y voto en sus experiencias de aprendizaje. “[...] los intelectuales transformativos necesitan desarrollar un discurso que conjugue el lenguaje de la crítica con el de la posibilidad, de forma que los educadores sociales reconozcan que tienen la posibilidad de introducir algunos cambios" (Giroux, 1997, p. 66). El maestro no puede limitarse a una crítica del estado de cosas actual sino que debe trascender esta función para ser también gestor de cambios, no sólo debe criticar, sino también proponer.

Ahora bien, queda la pregunta: ipuede esta idea del maestro como intelectual transformativo ser compatible con un ideal de educación moral que exige la formación de individuos autónomos, libres y críticos, con capacidad de auto-legislarse? La referencia hecha más arriba a la incompatibilidad de este ideal con las "pedagogías de la gestión” perfila una respuesta a esta pregunta, y más aún si se tiene en cuenta que la idea del maestro como intelectual transformativo es contraria a las "pedagogías de la gestión”.

En efecto, el maestro como intelectual transformativo es capaz de llevar a cabo el ideal de educación moral que está en juego porque posee ciertas características que lo permiten. Es el caso, por ejemplo, de la condición de crítica y reflexión. Gracias a este criterio el maestro es capaz de formar sujetos autónomos capaces de dar cuenta de los motivos de sus acciones y ser consecuentes con sus consecuencias. Además, en caso de dilema4, pueden reflexionar críticamente en torno a la decisión más adecuada según la situación.

Igualmente, si los maestros como intelectuales transformativos tienen el deber de “ejercer activamente la responsabilidad de plantear cuestiones serias acerca de lo que ellos mismos enseñan, sobre la forma en que deben enseñarlo y sobre los objetivos generales que persiguen" (Giroux, 1997, p. 65), entonces son los más indicados para la tarea de enfrentarse a un ethos mestizo como el que se describió en la introducción de este trabajo. En efecto, a un ethos de tales características no se le puede aplicar un currículo que haga abstracción de las particularidades, un currículo general y estandarizado, porque eso llevaría invariablemente al fracaso. Por el contrario, un intelectual transformativo es capaz de reflexionar en torno a las particularidades de cada contexto para seleccionar: las formas de conocimiento, los usos lingüísticos, las relaciones sociales, los valores y las formas particulares de vida social que sean pertinentes para un ethos tan variopinto como el propio de la sociedad colombiana. Más aún, esta característica del maestro actúa como una especie de provocación que "permite al discípulo elevar su pensamiento y encontrar caminos, no siempre

\footnotetext{
4 Entiéndase por dilema una situación problemática en la que entran en conflicto dos o más valores, y en la que es imposible evitar todas las consecuencias desagradables de la decisión que se tome. Para una mayor ilustración sobre dilemas morales véase el dilema del prisionero o el dilema de Heinz en J. Rachels (2007).
} 
similares a los de su enseñante, que le permitan ser sujeto ético, emancipado y por qué no, guía para otros, a su debido tiempo” (López, Marroquín y Rodríguez, 2014, p. 66).

Finalmente, la continua relación entre teoría y praxis con la que se encuentra comprometido el maestro como intelectual transformativo, lo hace el más indicado para la instrucción moral, pues le permite desarrollar el tipo de acciones performativas que le son propias a la moral. En la moral no hay cuestiones terminadas, ya que el proceso de hacernos seres morales es un proceso que nunca termina, como lo afirma Kant (1991) siempre tendremos que velar por que nuestras acciones sean correctas, la tarea de hacernos morales nunca llega a su fin.

En este orden de ideas, podemos concluir que la noción del maestro como intelectual transformativo de Henry Giroux (1990, 1997) permite llevar a cabo el ideal de formación ética de Esperanza Guisán (1995) (que devengamos individuos autónomos, libres y críticos, con capacidad de auto-legislarnos), gracias a que de las características con las que debe contar este tipo de maestro se sigue un modelo pedagógico que permite llevar a cabo dicho ideal.

Resta, pues, para finalizar el trabajo, analizar si un concepto de maestro como intelectual transformativo es compatible con la legislación educativa colombiana y con las políticas educativas en torno a la enseñanza de la ética, sobre todo en las condiciones actuales en las que, como sostiene Espino, "la sociedad civil y el Estado parecen haber redescubierto la importancia central de lo educativo" (Espino, 2009, p. 214).

\section{Políticas educativas, formación moral e intelectuales transformativos}

En este último parágrafo la tarea es mostrar que las políticas educativas en Colombia posibilitan la aplicación de un modelo pedagógico basado en las características del maestro como intelectual transformativo y que además está acorde con las características de la educación moral ya descritas. Esta tarea se lleva a cabo en dos momentos. En el primero de ellos se explora en la normatividad general las bases para las ideas propuestas, más precisamente en la Constitución Política de 1991 y en la Ley 115 de 1994; en el segundo momento la atención se concentra en los pasajes de los lineamientos curriculares para la enseñanza de la ética que apoyan la tesis inicial.

En la actualidad se suele recurrir mucho al lenguaje de los derechos en los debates de filosofía moral, ya que permite partir de unos mínimos necesarios que le son inherentes a cada persona. La Constitución Política de Colombia, en su Artículo 67, tipifica la educación como "un derecho de la persona y un servicio público que tiene una función social”, por lo que de entrada se está cumpliendo el criterio de inalienabilidad de la educación, el cual se hace extensible al ámbito de la ética cuando en la Ley General de Educación (MEN, 1994), se establecen como fines que se deben desarrollar a través de todos los niveles educativos, con el propósito del desarrollo integral de los educandos, los siguientes: “(a). Formar la personalidad y la capacidad de asumir con responsabilidad y autonomía sus derechos y deberes. Y (b). 
Proporcionar una sólida formación ética y moral, y fomentar la práctica del respeto a los derechos humanos" (MEN, 1994, art. 13). Lo interesante con el numeral (b) del artículo 13 es que no se especifica lo que significa "una sólida formación ética y moral", lo que permite explotar la posibilidad que se le abre al maestro como intelectual transformativo de plantear cuestiones serias acerca de lo que ellos mismos enseñan, sobre cómo deben enseñarlo y sobre los objetivos generales que persiguen, es decir, deja abierta la posibilidad de desarrollar un currículo en ética que atienda al contexto y, para nuestro caso particular, que pueda lidiar con los diferentes matices del ethos mestizo que caracteriza a la población colombiana.

Igualmente, en la Ley 115 de 1994 se establecen como fines de la educación: “(1) El pleno desarrollo de la personalidad sin más limitaciones que las que le imponen los derechos de los demás y el orden jurídico, dentro de un proceso de formación integral, física, psíquica, intelectual, moral, espiritual, social, afectiva, ética, cívica y demás valores humanos" (MEN, 1994, art. 5), lo que muestra un compromiso fuerte con el criterio de sociabilidad (el hombre debe convivir con sus semejantes para poder sobrevivir) y de autogobierno que implica nuestro objetivo de formación ética. Asimismo, “(2) La formación con el respeto a la vida y a los demás derechos humanos, a la paz, a los principios democráticos de convivencia, pluralismo, justicia, solidaridad y equidad, así como el ejercicio de la tolerancia y la libertad" (MEN, 1994, art. 5). Aquí es pertinente hacer énfasis en la última frase del enunciado como asegura el ejercicio de la libertad, otro de los criterios que se muestran en el fin de la educación moral que hemos venido manejando.

Finalmente, se determina como área obligatoria y fundamental la educación ética y los valores humanos (MEN, 1994, Art. 23) y se señala que:

La formación en ética y moral se promoverá en el establecimiento educativo a través del currículo, de los contenidos académicos pertinentes, del ambiente, del comportamiento honesto de los directivos, educadores y personal administrativo, de la aplicación recta y justa de las normas de la institución, y demás mecanismos que contemple el Proyecto Educativo Institucional (MEN, 1994, Art. 25).

Lo que hace extensible la tarea del maestro, en nuestro caso como intelectual transformativo, a lo que el Decreto 1278 (2002) llama "actividades curriculares no lectivas”, es decir, ya el maestro no limita su área de influencia sólo al aula, sino también a la comunidad educativa en general, de manera que su actividad políticopedagógica pueda ser llevada a cabo de manera más influyente.

Por lo que, en suma, podemos decir que la legislación colombiana, en general, está en sintonía con la formación en ética, o por lo menos no la restringe en gran medida. Por otro lado, con respecto a la idea del maestro como intelectual transformativo, se pueden encontrar algunas particularidades en los estatutos docentes que pueden minar la labor del docente colombiano. No obstante, allí hay un punto donde el maestro como intelectual transformativo tiene que dar la discusión y movilizar 
acciones de resistencia desde su propio hacer pedagógico-político. Miremos ahora qué nos dicen específicamente los lineamientos.

Uno de los elementos fundamentales de la formación moral de la persona es el proceso de construcción de la identidad que se da en el proceso de socialización. En los lineamientos curriculares para la enseñanza de la ética del MEN, este elemento se analiza de la mano de la teoría psicológica de Jean Piaget. Evidentemente, el proceso de socialización se da por parte de los adultos sobre los niños, tanto en la escuela como en la familia: “[...] los adultos como agentes socializadores somos inculcadores de valores, portadores de valoraciones y estamos continuamente haciendo de cierta manera un adoctrinamiento vivencial y ejercemos como educadores morales por diversos caminos en la cotidianeidad de la vida familiar y escolar" (MEN, 2011, p. 27).

En este proceso de recibir de la cultura los valores que le son propios, de interpretarlos e interiorizarlos, el niño va constituyendo su personalidad moral, va construyendo su identidad. Bajo estas coordenadas, entonces:

[...] la socialización hace referencia a la construcción de identidad, de un sentido de pertenencia que tiene múltiples coordenadas: pertenencia a una familia, a un grupo o grupos, a una comunidad, a una región, a un país pero también a una comunidad muy particular como es la humanidad (MEN, 2011, p. 27).

Para describir este proceso, los lineamientos se basan en las teorías de Piaget, Kohlberg, Freud y Vygotsky (MEN, 2011), siendo los dos primeros fuertemente influenciados por la filosofía kantiana y por el principio de autonomía que postula el filósofo alemán y que se trató más arriba. Según la interpretación de Anne-Marie Pieper de la obra de Piaget, el desarrollo moral del niño parte de un ser anómico, es decir que carece de normas y de criterios para definir qué es bueno y qué es malo, qué es correcto y qué es incorrecto, qué es justo y qué es injusto. El objetivo final es lograr que el sujeto devenga autónomo, que sea capaz de autolegislarse y de vivir en comunidad con sus semejantes. En el intermedio de este proceso hay diversas etapas de heteronomía, es decir, momentos en los que las normas y su carácter normativo le vienen impuestos por una autoridad exterior, sea el padre, el maestro o cualquier otro (Pieper, 2003).

En este punto ya se puede ver una sintonía de los lineamientos con la tesis que se está tratando de demostrar. El hecho de que tanto en el propósito de la educación moral como en el desarrollo de la construcción de la identidad el objetivo sea alcanzar la autonomía, es prueba suficiente de esta sintonía. Pero analizando el lugar que cumplen los adultos en el tránsito de la anomia a la autonomía, nos podemos dar cuenta de que el personaje ideal para cumplir ese rol es el maestro, en su papel de intelectual transformativo.

El primer punto relevante para evidenciar la idea que acabo de postular es el lugar privilegiado que les otorgan estos autores a las condiciones cognitivas del sujeto. "Autores como Piaget y Kohlberg les dan una gran importancia a los factores 
cognitivos, en el paso de la moral del deber y la costumbre a la moral autónoma." (MEN, 2011, p. 31). Estos factores cognitivos permiten que el sujeto pueda tomar distancia de los condicionamientos de la cultura en la que nace, aunque esto no excluye el hecho de que estas condiciones culturales tengan peso e importancia en la constitución de la persona moral. De aquí se puede concluir que el maestro, como intelectual transformativo, puede elegir contenido para el currículo que desarrolle las capacidades cognitivas al máximo de los sujetos en formación y acelerar este proceso de moralización. Igualmente, la elección de cultura que se realice en la planeación curricular cumple un papel importante en este proceso.

Un punto que es preciso enfatizar aquí, con respecto a la construcción de la persona moral, es la importancia para el sujeto de construirse un proyecto de vida,

[y] la necesidad de que las prácticas educativas ayuden a crear las condiciones que le permitan hacerse cargo de sí y avanzar en la búsqueda de caminos para llevar a cabo su idea de vida buena, en dirección a su realización personal (MEN, 2011, p. 31).

Cobra aquí nuevamente importancia el principio de autonomía kantiano, pues se trata es de que el niño construya su propio camino, pero que sea el maestro quien le dé las herramientas para desarrollarlo.

Finalmente, hay un punto en la teoría piagetiana que va en contra de las opiniones cotidianas respecto de los procesos de socialización y moralización. Es frecuente que se crea que estos procesos son unilaterales e impositivos. Sin embargo, "en términos piagetianos, la socialización está enmarcada en dos tipos de procesos, en dos tipos de relaciones sociales: unas de presión y otras de cooperación, una moral de la obediencia y una moral racional” (MEN, 2011, p. 32), una moral heterónoma y otra autónoma. El trabajo de los adultos es poner el primer elemento de estos pares conceptuales, el de los niños, construir el segundo.

Esta relación transcurre en algunas ocasiones en situaciones de tensión y de cierta violencia. "La inscripción del niño en una normatividad implica conflicto, implica un cierto grado de violencia simbólica, inevitable podría decirse” (MEN, 2011, p. 32). A menudo el adulto parte de la heteronomía para mantener al niño sumiso y obediente a sus mandatos; el verdadero problema no es que el niño inicialmente obedezca sino que esta relación se perpetúe. Para evitar este peligro es fundamental el carácter crítico y reflexivo del maestro como intelectual transformativo.

Finalmente, podríamos otorgarle a la escuela en cabeza del maestro como intelectual transformativo una tarea muy especial: "crear el puente entre estos dos tipos de moral, como facilitadora de vivencias, de experiencias, de estrategias, que le permitan al niño y al joven avanzar en el proceso de construcción de una moral autónoma" (MEN, 2011, p. 32). 


\section{Consideraciones finales}

Miremos atrás a ver cuánto hemos avanzado. Partimos de la introducción histórica presentada en los Lineamientos curriculares para la enseñanza de la ética del MEN, para describir las características culturales de la sociedad colombiana a través del concepto Ethos mestizo. El colombiano, como producto que es de un mestizaje, reúne en su persona las ideas individualistas propias de la Europa de la modernidad, la férrea fe del Imperio español y las tradiciones autóctonas de los nativos. Esta circunstancia hace que la educación en ética necesaria en estas tierras sea muy sui generis. Por eso se aborda la cuestión de la educación moral desde la propuesta de Esperanza Guisán, para quien es fundamental que se tomen en cuenta tanto la socialización como la moralización, procesos que se complementan para alcanzar el ideal normativo que se considere más adecuado para la sociedad en cuestión.

Posteriormente, se estudió la diferencia entre una educación basada en las "pedagogías de la gestión” y una educación basada en los ideales emancipadores de un maestro como intelectual transformativo. El análisis mostró que una educación ética que atienda las ideas de Guisán requiere que el maestro no sea un mero "técnico del currículo", como sucede en las "pedagogías de la gestión”, sino un sujeto político que luche por alejar a los estudiantes de la enajenación generalizada a la que se ven sometidos por la tecnocracia que domina hoy el currículo.

Finalmente, se revisaron algunas normas fundamentales de la legislación colombiana en las que se evidenciaba la relación de la educación y la ética. Esta revisión arrojó que, contrario a lo que se podría creer, la legislación no restringe la actuación de los maestros de ética a la reproducción de contenidos preestablecidos, sino que les brinda la libertad de poner en juego sus facultades y conocimientos para lograr una verdadera transformación en sus estudiantes. No obstante, esta libertad es un arma de doble filo. Si los maestros se comportan como técnicos del currículo lograrán que sus estudiantes se sumerjan cada vez más en la alienación generalizada de esta sociedad. Pero si, por el contrario, los maestros actúan como intelectuales, podrán lograr muchos cambios sin verse restringidos por el imperio de la ley.

Con lo dicho hasta aquí se ha argumentado lo suficiente para probar la tesis que se postuló en la introducción. La relación entre formación moral, maestro como intelectual transformativo y los lineamientos curriculares para la enseñanza de la ética no es sólo posible, sino que también es probable, más aún, puede llegar a ser incluso necesaria si se atiende a las formas particulares en las que la sociedad actual se desarrolla. Esto no quiere decir que la tarea esté terminada; muy por el contrario, este trabajo sólo funciona como una especie de diagnóstico preliminar. Queda, pues, como tarea estudiar los contextos específicos para crear mallas curriculares específicas, acordes con el ethos peculiar de cada comunidad. Pero eso escapa a los límites de este trabajo. Sin embargo, se ha mostrado lo pertinente que es el concepto de maestro como intelectual transformativo' en las reflexiones en torno a la enseñanza de la ética en Colombia, y eso ya es una gran ganancia para lograr una transformación de la sociedad colombiana, lo que, en últimas, es lo que debe buscar todo intelectual transformativo, en particular si ese intelectual es un maestro. 


\section{Referencias}

Bustamante, G. (2012). Pedagogía de Kant, ¿una filosofía de la educación? Magis, 5(10), 155-172.

Constitución Política de Colombia (1991). Recuperado de: http://www. corteconstitucional.gov.co/inicio/Constitucion\%2opolitica\%2ode\%20 Colombia\%20-\%202015.pdf

Dancy, J. (1995). El intuicionismo. En P. Singer (Ed.), Compendio de Ética (pp. 555-566). Traducción de J. Vigil Rubio y M. Vigil. Madrid: Alianza.

Espino, E. (2009). Semiótica y ética de la relación pedagógica. Educación y Educadores, 7, 213-220.

Giroux, H. (1990). Los profesores como intelectuales. Madrid: Centro de Publicaciones del Ministerio de Educación y Ciencia.

Giroux, H. (1997). Los profesores como intelectuales transformativos. En Los profesores como intelectuales: Hacia una pedagogía crítica del aprendizaje. Barcelona: Editorial Paidós.

Guisán, E. (1995). Introducción a la ética. Madrid: Cátedra.

Kant, I. (1991). Pedagogía. Madrid: Akal.

Kant, I. (1994). Respuesta a la pregunta: qué es la ilustración. Revista Colombiana de Psicología, 3, 7-10.

López A., G., Marroquín N., L., y Rodríguez B., A. (2014). El maestro como arquitecto y constructor de pensamiento. Revista Fundación Universitaria Luis Amigó, 1(1). doi: https://doi.org/10.21501/23823410.1201

Ministerio de Educación Nacional —MEN_ de Colombia (1994). Ley 115 de 1994. Por la cual se expide la ley general de educación. Recuperado de: https://www. mineducacion.gov.co/1621/articles-85906_archivo_pdf.pdf

Ministerio de Educación Nacional - MEN- de Colombia (2002, junio). Decreto 1278 de 2002. Por el cual se expide el Estatuto de Profesionalización Docente. Recuperado de: https://www.mineducacion.gov.co/1621/articles-86102_ archivo_pdf.pdf

Ministerio de Educación Nacional - MEN - de Colombia (2011). Lineamientos curriculares del MEN para el área de ética y valores. Recuperado de: https:// www.mineducacion.gov.co/cvn/1665/articles-89869_archivo_pdf7.pdf

Pieper, A. M. (2003). Ética y moral: Una introducción a la filosofía práctica. Barcelona: Editorial Crítica.

Platón (1988). Diálogos. Menón. Bogotá: Áncora Editores.

Rachels, J. (2007). Introducción a la filosofía moral. México: FCE.

Tugendhat, E. (2007). El problema de una moral autónoma. En Antropología en vez de Metafísica. Barcelona: Gedisa. 